\title{
A strict Positivstellensatz for enveloping algebras
}

\section{Konrad Schmüdgen}

Published online: 15 January 2008

C Springer-Verlag 2008

Erratum to: Math. Z. (2006) 254:641-653

DOI 10.1007/s00209-006-0965-3

There are some misprints in the formulation of Theorem 1.1 on p. 642. Assumption (i) therein should be read as follows:

(i) There exists $\varepsilon>0$ such that $d U_{\alpha}(c-\varepsilon \cdot 1) \geq 0$ for all $\alpha \in \mathcal{K}_{f}$.

The online version of the original article can be found under doi:10.1007/s00209-006-0965-3.

K. Schmüdgen $(\varangle)$

Fakultät für Mathematik und Informatik, Universität Leipzig, Augustusplatz 10,

04109 Leipzig, Germany

e-mail: schmuedgen@math.uni-leipzig.de 